\title{
The shape of warmth: temperature profiles in living rooms
}

\section{Gesche M. Huebner, Megan McMichael, David Shipworth, Michelle Shipworth, Mathieu Durand-Daubin \& Alex J. Summerfield}

To cite this article: Gesche M. Huebner, Megan McMichael, David Shipworth, Michelle Shipworth, Mathieu Durand-Daubin \& Alex J. Summerfield (2015) The shape of warmth: temperature profiles in living rooms, Building Research \& Information, 43:2, 185-196, DOI: 10.1080/09613218.2014.922339

To link to this article: https://doi.org/10.1080/09613218.2014.922339

\section{(c) 2014 The Author(s). Published by Taylor \& Francis.}

曲 Published online: 19 Jun 2014.

\section{Submit your article to this journal}

Џلll Article views: 1341

Q View related articles ¿

View Crossmark data $₫$

那

Citing articles: 4 View citing articles $ک \pi$ 


\title{
RESEARCH PAPER
}

\section{The shape of warmth: temperature profiles in living rooms}

\author{
Gesche M. Huebner ${ }^{1}$, Megan McMichael ${ }^{1}$, David Shipworth ${ }^{1}$, Michelle Shipworth", \\ Mathieu Durand-Daubin ${ }^{2}$ and Alex J. Summerfield ${ }^{1}$
}

\author{
${ }^{1}$ UCL Energy Institute, University College London, 14 Upper Woburn Place, London WC1H ONN, UK \\ E-mails: g.huebner@ucl.ac.uk,m.mcmichael@ucl.ac.uk, d.shipworth@ucl.ac.uk,m.shipworth@ucl.ac.uk \\ and a.summerfield@ucl.ac.uk \\ ${ }^{2}$ EDF R\&D, 1, avenue du Général de Gaulle, F-92140 Clamart, France \\ E-mail: mathieu.durand-daubin@edf.fr
}

\begin{abstract}
The most commonly used family of models in representing the UK building stock, BREDEM (the Building Research Establishment Domestic Energy Models), assume that all homes exhibit the same heating pattern and hence can be expected to have similar temperature profiles over the course of a day. The presented research shows that homes differ significantly in their respective temperature profile over the course of the day. A cluster analysis performed on temperature data from 275 living rooms in English homes over three winter months resulted in four different clusters of temperature profiles. The clusters differ significantly in their shape, as revealed by visual inspection, and supported by significant differences in minimum and maximum temperatures and temperature variability across the day. About $40 \%$ of homes showed a bimodal temperature pattern as assumed under BREDEM. However, the remaining $60 \%$ showed very different profiles. These findings challenge the assumption that one standard pattern fits all homes. Different temperature demand profiles have important implications for future peak power demands, particularly if domestic space heating is switched to electricity. It is also helpful for relating occupant demographics to appropriate forms of fabric retrofit.
\end{abstract}

Keywords: consumption practices, heating patterns, housing, occupancy schedules, occupant behaviour, space heating demand, temperature profiles

\section{Introduction}

Home energy consumption comprises approximately $32 \%$ of all energy use in the UK with space heating the largest contributor (Committee on Climate Change, 2010). Consequently, it is an important target area for energy reduction in order to meet the UK government target of reducing carbon emissions by $80 \%$ by 2050 (Department for Energy and Climate Change, 2008). The heating demand temperature (which usually reflects the thermostat set-point temperature used in a dwelling to control the heating system) and the duration of heating period (i.e. the number of hours that the heating system is on) have the greatest influence on a home's space heating energy use and associated $\mathrm{CO}_{2}$ emissions, as revealed by sensitivity analysis conducted on BREDEM (Building Research Establishment Domestic Energy Model) class models (Firth, Lomas, \& Wright, 2010; Hughes, Palmer, Cheng, \& Shipworth, 2013). Several papers have examined internal temperatures (see below), but in particular the variability between homes and the time course of temperatures over a day has received little attention.

In the UK, the most commonly used models for modelling the building stock belong to the BREDEM family (see Kavgic et al., 2010, for a review of UK residential stock models). These models usually use default assumptions on how homes are heated and to what temperature. BREDEM models are driven by an 'occupancy schedule' that is set externally to the model and which can be varied by the model user. This stipulates that the living room is heated to $21^{\circ} \mathrm{C}$ for nine hours on weekdays (07.00-09.00 and 16.00-23.00) and for 
16 hours on weekends (07.00-23.00) (Anderson et al., 2002). Between these periods, the model assumes the heating is switched off, and the house cools in accordance with an estimate of the envelope heat loss largely determined by the thermal time-constant of the fabric and ventilation losses. Internal temperature thus exponentially decays from the set-point until the subsequent heating period commences. However, as Oreszczyn and Lowe (2004) point out, there are little data that could validate the BREDEM model or capture the variations in occupant behaviour known to occur in the stock. In fact, estimates of energy demand made with these models have been shown to be a poor predictor of actual energy consumption (Kelly, 2011), and a recent paper showed that homes vary widely in their temperatures during those time windows when models would assume them to have $21^{\circ} \mathrm{C}$ (Huebner et al., 2013).

The BREDEM-based models serve several primary purposes. As part of regulatory instruments, like the Standard Assessment Procedure (SAP), the UK government's primary assessment mechanism for determining energy efficiency of homes, they set standards for energy use against which individual dwelling design proposals are evaluated for compliance. That is, they serve a normative function representing how the fabric and heating technology in dwellings should perform; they standardize occupant influences in order to assess the building performance independently of occupant effects. In this case, a consideration of variability in internal temperatures and heating behaviour would indeed be opposed to the purpose of the modelling, and it is of secondary importance whether the assumed behaviour reflects the average actual behaviour. However, BREDEM-based models are also used to estimate an individual consumer's likely energy savings following energy efficiency retrofits. This is done by calculating the current and possible future SAP ratings and estimated energy consumption. These calculations of course use the standardized SAP ratings. However, the huge range in actual temperature profiles indicates that the energy saving estimates based on SAP are likely to be quite misleading for a large proportion of households; some will save much more and some much less than predicted. Moreover, when BREDEM-based models are used as the basis for building stock modelling, their purpose is to indicate how homes (i.e. occupied houses) actually perform. In this function it is of primary importance that they correctly represent occupant influences in order to estimate correctly national energy demand from the nation's homes.

In general, it has been recognized that both human factors and building characteristics impact on energy consumption in domestic households (e.g. Allcott \& Mullainathan, 2010; Dietz, Gardner, Gilligan, Stern, \& Vandenbergh, 2009; Druckman \& Jackson, 2008;
Gill, Tierney, Pegg, \& Neil, 2010; Lutzenhiser, 1993; Shorrock \& Utley, 2008; Utley \& Shorrock, 2006). These and other studies have addressed energy consumption in general, but very few have addressed heating demand temperature and patterns in particular. Kelly et al. (2013) developed a model for predicting daily mean internal temperature that was able to explain $45 \%$ of the variance of internal temperature between dwellings. Behavioural, socio-demographic and building energy efficiency variables were used as predictors and contributed to predicting the mean internal winter temperature in the English housing stock as a whole to within approximately $0.71^{\circ} \mathrm{C}$ at a $95 \%$ confidence interval. Some of the significant predictors were the presence of children or retired occupants, building characteristics such as roof insulation, wall $U$-values, building type and the presence of thermostats or thermostatic radiator valves. Oreszczyn, Hong, Ridley, and Wilkinson (2006) found that similar socio-demographic variables, such as the age of householders and number of people, and buildingdemographic variables, such as construction and thermal efficiency, influenced internal temperatures of low-income households. Similarly, Hunt and Gidman (1982) found that internal temperatures in their UK sample varied according to dwelling type and tenure. They also found that those with low incomes had cooler homes and the presence of young children or elderly residents affected temperatures. In a crosssectional survey where space heating energy consumption was derived from energy bills, Cayla, Allibe, and Laurent (2010) further found that standard sociodemographic variables such as age and income were indicative in explaining variance in heating-related energy use in a sample homes in France, even more than self-reported indications of heating and energy practices (e.g. window opening). In a nationally representative study of New Zealand homes, of which only $5 \%$ are centrally heated, French, Camilleri, Isaccs, and Pollard (2007) found that winter living room temperatures averaged $17.9^{\circ} \mathrm{C}$. They further found no significant correlations between mean internal winter temperatures and income, though they did find correlations with house age (older houses were cooler) and the main driver for mean living room temperatures was the type of heating system. In a small Danish sample of low-energy homes, Isaksson and Karlsson (2006) also found internal temperature differences related to type of housing. Shipworth et al. (2010) used measured internal temperature to estimate thermostat settings and heating duration patterns. They found average maximum internal temperature for three winter months, used as a proxy for the thermostat setting, was $21.1^{\circ} \mathrm{C}$, in line with the heating demand temperatures as assumed by BREDEM-based models. Average estimated heating duration was 8.2 hours for weekdays and 8.4 hours for weekends. Importantly, the analysis of Shipworth et al. (2010) revealed large variability in the data, in particular 
regarding heating demand temperature (standard deviation $(\mathrm{SD})$ of $2.5^{\circ} \mathrm{C}$ ). For heating duration estimates the $\mathrm{SD}$ was 1.5 hours.

Whilst those studies provide some insight on levels and determinants of internal temperatures, to our knowledge no national study has explicitly addressed the patterns of how temperatures vary over the course of a day. Do they follow the standard weekday and weekend patterns of heating as assumed by BREDEM, i.e. display a profile of internal temperatures with a peak in the early morning and a peak in the evening for weekdays (termed the 'bimodal' pattern) and continuous temperatures from 7.00 to 23.00 hours on weekends, or do distinctly different patterns of internal temperatures exist?

This question is of importance for several reasons. It is plausible that different temperature profiles are characterized by different levels of internal temperature, with varying hours of heating and levels of energy demand. In this case:

- The prediction of future energy demand might be incorrect when using default values. In future, significant demographic change is expected with an ageing population and more, but smaller, households. If certain profiles with different energy consumptions are linked to certain segments of the population, predictions of future energy demand could be incorrect.

- The imprecision for predicting energy consumption of individual homes or the inaccuracy for predicting energy consumption of sectors of homes would be considerable.

- Through failing to represent the range of observed temperature profiles in the stock as a function of building-demographic and socio-demographic variables, assuming profiles can be linked to such explanatory variables, the opportunity is lost to target policy interventions to specific demographic segments.

Even if energy demand did not vary across different temperature profiles, the finding of distinct temperature profiles would be of interest. They would indicate that homes are used in different ways (assuming that cluster membership would not be entirely determined by building factors) and could reveal different comfort requirements. Moreover the timing of heating demand greatly affects the energy demanded by the system over the course of the day. This is particularly important if, as is currently planned, more UK heating was to be provided by electricity. In this case knowledge about whether the demand for high temperatures (as a proxy for heating) would be the same in all buildings or would be spread out would be of importance in designing the energy supply system. The aim of this paper is to test if internal temperatures in homes follow one standard pattern or whether they exhibit distinctly different temporal profiles. Cluster analysis (CA) is used here to identify patterns of internal temperatures, and link them to socio-demographic variables (e.g. age, income, tenure and household size) and building-demographic variables (e.g. type of housing and heating system). The basic idea behind CA is to group entities (here, households) on the basis of their similarity regarding selected variables (here, temperatures over the day) so that households in one group are as similar as possible to other households in that group (i.e. high withingroup homogeneity) and as dissimilar as possible to households in other groups (low between-group homogeneity) (Clatworthy, Buick, Hankins, Weinman, \& Horne, 2005).

This analysis provides a first step in moving away from default heating patterns for the whole population. Internal temperatures are often considered a proxy for heating patterns; however, it should be kept in mind that temperatures do not necessarily correspond to heating patterns. A range of factors may lead to internal temperature profiles differing from heating demand patterns, including various forms of incidental gains and ventilation heat losses.

\section{Methods}

\section{Survey and temperature measurements}

The data analysed in this paper are taken from the Carbon Reduction in Buildings Home Energy Survey (CaRB HES), the first national survey exclusively focused on energy use in English homes ${ }^{1}$ that commenced in early 2007 (for details, see Shipworth et al., 2010). Households were selected by stratified random sample drawn from the postcode address file. Sampling and face-to-face interviews in 427 homes were carried out by the National Centre for Social Research (NatCen). During the interview, householders answered questions on the building characteristics of their home, heating practices and socio-demographics (for details, see Table A1 in Appendix A). For a subset of homes, temperatures were monitored in the bedroom and living room from mid-July 2007 to early February 2008. HOBO UA 001-08 sensors were used, which are self-contained data loggers programmed to record spot temperature every $45 \mathrm{~min}$, resulting in 32 measurements per day. They were placed in the home by the interviewer and/or homeowner with instructions on correct placement, i.e. between knee and head height, away from any heat sources or direct sunlight. The sensors have a manufacturer reported accuracy of $\pm 0.47^{\circ} \mathrm{C}$, however calibration measurements were taken for 
each logger before placement in the home and used to correct subsequent readings after the recorded data had been extracted.

\section{Overview of sample}

Table 1 summarizes key characteristics of the CaRB HES data with $N=275$ dwellings in comparison with the nationally representative English House Condition Survey (EHCS) 2007/08 (Department for Communities and Local Government, 2010, 2011).

Table 1 Key characteristics of Carbon Reduction in Buildings Home Energy Survey (CaRB HES) and EHCS

\begin{tabular}{|c|c|c|}
\hline Variable & $\begin{array}{l}\text { CaRB HES } \\
2007 / 08 \\
\text { (valid \%) }\end{array}$ & $\begin{array}{l}\text { English House } \\
\text { Condition Survey } \\
\text { (EHCS) } 2007 \text { (\%) }\end{array}$ \\
\hline \multicolumn{3}{|l|}{$\begin{array}{l}\text { Age (Average value, } \\
\text { not per cent) }\end{array}$} \\
\hline Mean HRP age & 55.7 & 52.4 \\
\hline Mean age of youngest & 42.6 & 38.4 \\
\hline Mean age of oldest & 57.2 & 53.5 \\
\hline \multicolumn{3}{|l|}{ Tenure type } \\
\hline Owner occupied & 81.8 & 71.2 \\
\hline Privately rented & 5.1 & 11.6 \\
\hline Local authority & 6.6 & 8.8 \\
\hline $\begin{array}{l}\text { Housing association } \\
\text { and social landlord }\end{array}$ & 6.6 & 8.4 \\
\hline \multicolumn{3}{|l|}{ Dwelling type } \\
\hline Terraced & 20.7 & 27.9 \\
\hline Semi-detached & 22.4 & 27.8 \\
\hline $\begin{array}{l}\text { Bungalow or detached } \\
\text { house }\end{array}$ & 41.1 & 27.8 \\
\hline Flats & 12.0 & 16.6 \\
\hline Other & 1.8 & \\
\hline \multicolumn{3}{|l|}{ Dwelling age } \\
\hline Pre-1919 & 13.1 & 21.1 \\
\hline $1919-44$ & 16.8 & 17.5 \\
\hline $1945-64$ & 23.4 & 19.7 \\
\hline $1965-80$ & 26.3 & 21.8 \\
\hline Post-1981 & 20.5 & 19.9 \\
\hline $\begin{array}{l}\text { Total number of } \\
\text { households in the } \\
\text { survey }\end{array}$ & 275 & 21380 \\
\hline
\end{tabular}

Note: $\mathrm{HRP}=$ household reference person
As shown in Table 1, the CaRB HES sample over-represents owner-occupied dwellings, as well as the dwelling type category 'bungalows or detached houses'. Also of note, $84 \%$ of the CaRB HES sample had gas central heating (either gas or liquefied petroleum gas - LPG) as compared with $87 \%$ in the EHCS (Nowak, 2009).

\section{Pre-processing of temperature data}

For the present paper, only living room data in the winter months were used. Winter was defined as ranging from 1 November 2007 to 31 January 2008 and, hence, encompassed the three months November 2007, December 2007 and January 2008. The temperature loggers were withdrawn after 31 January 2008; since the date of removal in February 2008 varied across households, only temperature data until 31 January were considered to ensure the same data range in all households. A variable expressing average daily external temperature was created based on minimum and maximum temperatures at local weather stations within the respondent's government office regions (Kelly et al., 2013). For no day or region in the data analyses for this paper did the average maximum external temperature exceed $15.5^{\circ} \mathrm{C}$; above this value, it is assumed that there is no need for heating (CarbonTrust, 2012). The recorded internal temperature data were screened for outliers, i.e. for recorded temperatures below $10^{\circ} \mathrm{C}$ or above $35^{\circ} \mathrm{C}$, and for changes of more than $10^{\circ} \mathrm{C}$ in $45 \mathrm{~min}$ (indicating placement close to a heating source or through exposure to direct sunlight). Those potentially erroneous data points occurred on fewer than $0.2 \%$ of days and were excluded from further analysis. The dataset was managed in MS Access and STATA and for this paper analysed using SPSS and MatLab.

\section{Cluster analysis}

A cluster analysis (CA) of the temperature data was conducted to identify typical profiles of temperatures in the home. CA is an exploratory data tool for organizing data into meaningful groups; it maximizes the similarity of cases within each cluster and maximizes the dissimilarity between groups that are initially unknown.

The temperature data for each dwelling were centralized by subtracting each day's average from the 32 individual measurement time points. Centralizing was done because the shape of the temperature profile was of primary interest, not the absolute temperature. The centralized data at the 32 measurement points for each day of the week were averaged across the different weeks. An agglomerative hierarchical clustering analysis was then performed, using Ward's minimum variance method based on the squared Euclidean 
distances between households described by temperature data consisting of 224 variables, i.e. 7 days by 32 measurement points. Entering each day separately gives adequate weight to weekdays (5 days) and weekends ( 2 days) that might differ in their temperature profile. Hierarchical clustering starts with each case as a separate cluster and then combines the clusters sequentially. The complete agglomerative process results in $N$ nested possible partitions (for details on this clustering method, see Ward, 1963). The changes in within-cluster variance after merging two clusters were examined in order to decide on the numbers of clusters, in addition to using a criterion of a minimum cluster size of ten observations. Once cluster membership for each home was established, subsequent analysis was conducted using absolute (i.e. not centralized) temperature data.

\section{Results}

\section{Cluster analysis (CA)}

Four clusters resulted from the hierarchical CA (Ward's method) on the centralized temperature data for all days. Figure 1(a) shows the mean temperature of all dwellings within each of the clusters for weekdays; Figure 1(b) for weekends.

Cluster 3 represents the largest cluster with $N=110$ dwellings $(40.0 \%$ of the sample referred to as 'two peak'), and corresponded most closely to the assumption of an occupancy pattern with two peaks, one in the morning and one in the early evening. The second most common cluster was cluster 2 , which represented $30.9 \%$ of the dwellings $(N=85$; 'flat line') and showed an almost flat temperature profile. Cluster 4 ( $N=38,13.8 \%$; 'steep rise') showed a decline until early morning followed by a steep increase until about 21.00 hours. Cluster $1 \quad(N=42,15.3 \%$; 'steady rise') similarly showed a decrease until the early morning hours followed by a steady increase, although on a lesser magnitude than cluster 4 . The cluster means for weekdays and weekends are similar, with the decrease after the first peak in cluster 2 less pronounced than on weekdays. Whilst this analysis does not show the occupancy schedules assumed by BREDEM, the emergence of four distinct clusters challenges the assumption that one occupancy pattern adequately represents reality.

\section{Average, minimum and maximum temperatures in the clusters}

Table 2 shows the average daily temperature, average maximum daily temperature and average minimum daily temperature for each cluster. For the average daily temperature, for each home, the temperature at each of the 32 measurement points was averaged (over all winter days); the resulting 32 values were then averaged (home average daily temperature) and then averaged across all homes in the cluster. For the maximum (minimum) temperature for each home, the maximum (minimum) temperature of the average values was identified at the 32 measurement points, then those maximum (minimum) values were averaged across all homes in one cluster.

Levene's $F$-test for equality of variances showed that variances in all variables of the table were not equal (i.e. were spread out differently far from the mean), making the use of statistical procedures necessary that do not make the assumption of variance homogeneity. Welch's test was used for multiple independent groups; and Games-Howell tests were used for posthoc pairwise comparisons.

The average temperature on weekdays and weekends was not significantly different in the four clusters. Considering that the CA was carried out on the centralized values, i.e. discounting absolute differences in temperatures, it is not a surprising finding that the daily average temperatures do not differ between the four clusters. It indicates though that a specific shape is not linked to higher or lower temperature. However, both the minimum and maximum temperatures (weekdays and weekends) differed significantly between the four clusters (all $F>$ 6.8 ; all $p \leq 0.002$ ). Pairwise comparisons showed that the weekday maximum temperature was significantly lower in cluster 2 than in clusters 1 and $4(p<0.001$ and $p=0.014$ ). For weekends, the maximum temperature in cluster 2 was lower than in all other clusters (all $p<0.028)$. Regarding the minimum temperatures, cluster 4 had a significantly lower temperature than all other clusters on both weekdays and weekends. No other differences were significant.

\section{Standard deviation over the course of a day in the different clusters}

The average standard deviation over the course of the day was calculated (Table 3). It is a way of expressing how much the temperature at the 32 measurement points varies around the daily mean. This was done in order to quantify the visual descriptions in Figures 1(a) and 1(b) of the 'flatness' or 'curviness' of each temperature cluster. A small standard deviation would indicate little variation around the daily mean; a large standard deviation more variation, i.e. more 'curving' of the profile over the day. For each dwelling, the standard deviation was calculated across the 32 measurement points of the temperatures averaged over all winter days. The value was then averaged across all the dwellings in each cluster.

A Welch test for multiple samples showed that standard deviations across the four clusters differed significantly (for weekdays: $F_{\text {Welch }}(3,102.95)=118.55$, $p<0.001$; for weekends $F_{\text {Welch }}(3,99.28)=110.97$, 

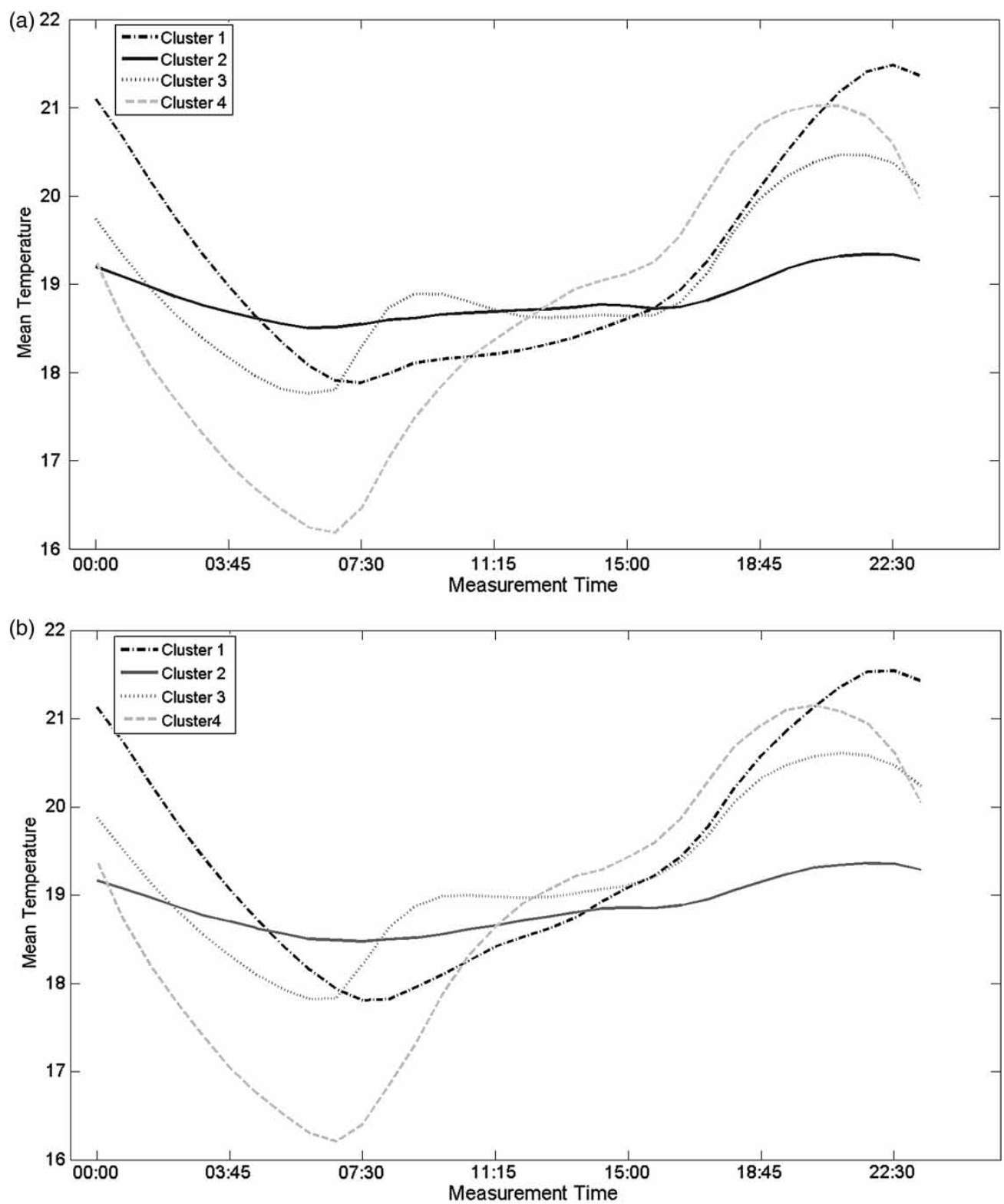

Figure 1 Average temperature profiles of the four cluster for weekdays (a) and weekends (b)

$p<0.001)$. Post-hoc pairwise Games Howell tests showed that all differences were significant, both for weekdays and weekends, all $p \leq 0.001$.

Cluster 2 (flat line) had the lowest standard deviation, meaning that values differed least around the mean. The largest standard deviation was found in cluster 4 (steep rise), in line with the very pronounced curving of the temperature line. Hence, the CA showed four distinctively different temperature profiles that could reflect the preferences and needs of occupants and/or building characteristics. The next step explored the characteristics underlying the four clusters.

\section{Relationship of clusters to building- and socio-demographic variables}

Previous research, as discussed in the introduction, has shown that a number of socio-demographic and building-demographic variables are related to energy consumption and temperatures (Cayla et al., 2010; Hunt \& Gidman, 1982; Kane, Firth, Allinson, Irvine, \& Lomas, 2010; Kelly et al., 2013; Oreszczyn et al., 2006). Hence, the need to relate variables of both types to cluster membership. Approximately 35 variables were tested, but only those variables that were found to be statistically significant are presented. The list of those variables not found to be statistically significantly are presented in Table A1 in Appendix A. 
Table 2 Averaged daily, maximum and minimum temperatures in the four clusters

\begin{tabular}{|c|c|c|c|c|c|c|}
\hline & \multicolumn{2}{|c|}{$\begin{array}{l}\text { Average daily temperature } \\
{ }^{\circ} \mathrm{C} \text { (SD) }\end{array}$} & \multicolumn{2}{|c|}{$\begin{array}{l}\text { Maximum of average daily } \\
\text { temperature }{ }^{\circ} \mathrm{C} \text { (SD) }\end{array}$} & \multicolumn{2}{|c|}{$\begin{array}{l}\text { Minimum of average } \\
\text { temperature }{ }^{\circ} \mathrm{C} \text { (SD) }\end{array}$} \\
\hline & Weekday & Weekends & Weekday & Weekends & Weekday & Weekends \\
\hline 1 (Steady rise) & $19.28(2.17)$ & $19.47(2.13)$ & $21.67(2.27)$ & $21.74(2.23)$ & $17.50(2.07)$ & $17.50(2.06)$ \\
\hline 2 (Flat line) & $18.85(2.98)$ & $18.87(2.93)$ & 19.66 (3.05) & $19.71(3.02)$ & $18.16(2.94)$ & $18.13(2.90)$ \\
\hline 3 (Two peak) & $19.00(2.05)$ & $19.23(2.03)$ & $20.63(2.17)$ & $20.79(2.10)$ & 17.52 (1.95) & $17.62(1.96)$ \\
\hline 4 (Steep rise) & $18.68(2.56)$ & $18.81(2.68)$ & 21.45 (2.91) & 21.51 (3.08) & $16.03(2.65)$ & $16.03(2.65)$ \\
\hline
\end{tabular}

Note: $\mathrm{SD}=$ standard deviation

Table 3 Average standard deviations (SDs) for weekdays and weekends in the four clusters

\begin{tabular}{lcc}
\hline Cluster & Mean SD weekday & Mean SD weekend \\
\hline 1 (Steady rise) & 1.32 & 1.34 \\
2 (Flat line) & 0.46 & 0.47 \\
3 (Two peak) & 0.94 & 0.97 \\
4 (Steep rise) & 1.76 & 1.80 \\
\hline
\end{tabular}

The associations between the clusters and each of the demographic and building variables were tested independently, meaning that inter-correlations between variables and the effect of one variable corrected for the effect of other variables were not considered. This approach to analysis should only be seen as a way of describing clusters, not as indicating causation.

One-way analysis of variance (ANOVA) was used to test for differences in continuous variables between clusters. All post-hoc tests in the ANOVA were Bonferroni corrected, i.e. the significance level for pairwise comparisons corrected for the number of comparisons in order to prevent problems associated with multiple comparisons.

Chi-square tests were used for differences in categorical variables. This analysis tests for the presence of a statistically significant relationship between two variables. When the chi-square test was significant, column properties were then compared to test which pair of columns (i.e. which clusters) for a given row differed significantly, again using Bonferroni correction.

\section{Socio-demographic factors}

Table 4 summarizes the results of chi-square tests for socio-demographic variables. Only those variables are shown where significant differences were found.
The value in each cell indicates the proportion of households that exhibit the respective variable as coded. The superscript letters indicate which proportions differed significantly; if two values do not share a letter, they are significantly different from each other, as, for example, clusters 4 and 3 in the first variable. If they share a letter, they are not significantly different.

To test for difference in continuous variables between clusters, ANOVA was used. The mean value for the respective variable in each cluster is shown in the cells in Table 5, again with superscript letters indicating significant differences in post-hoc pairwise comparisons (the respective test statistics are not shown for brevity).

The age of the oldest person and the household reference person $(\mathrm{HRP})^{2}$ is higher in cluster 4 (steep rise) than either clusters 2 or 3 , and cluster 4 has a larger proportion of persons over 79 than cluster 3. The mean age of the youngest person is significantly lower in cluster 2 (flat line) than clusters 1 or 4 , and the proportion of households with children under five years and of socially rented accommodation is greater than in cluster 1. For income, the gross household equivalized income was used. Cluster 3 (two peak) is characterized by significantly fewer households in the lower income bracket than cluster 1 (steady rise), and significantly more households in the higher income bracket than cluster 4 (steep rise).

There were no significant differences between clusters in the average number of bedrooms, the type of household, presence of dependent children and number of household members.

Building variables. Table 6 presents the distribution of building-related variables and clusters and follows the same form as the tables above. 
Table 4 Chi-squared analysis of socio-demographics variables between clusters

\begin{tabular}{|c|c|c|c|c|c|c|c|}
\hline \multirow[t]{2}{*}{ Variable } & \multicolumn{4}{|c|}{ Cluster number } & \multicolumn{3}{|c|}{ Test values } \\
\hline & 1 (Steady rise) & 2 (Flat line) & 3 (Two peak) & 4 (Steep rise) & $\chi^{2}$ & d.f. & $p$ \\
\hline \multicolumn{8}{|l|}{ Age } \\
\hline Person over 79 years present & $11.9 \%^{a, b}$ & $11.8 \%^{\mathrm{a}, \mathrm{b}}$ & $5.5 \%^{\mathrm{b}}$ & $23.7 \%^{\mathrm{a}}$ & 9.86 & 3 & 0.020 \\
\hline Person over 59 years present & $57.1 \%{ }^{a, b}$ & $37.6 \%{ }^{a, b}$ & $42.7 \%^{\mathrm{b}}$ & $68.4 \%^{\mathrm{a}}$ & 12.53 & 3 & 0.006 \\
\hline Person under 5 years present & $0.0 \%^{\mathrm{a}}$ & $15.3 \%^{\mathrm{b}}$ & $8.2 \% \%^{a, b}$ & $5.3 \%^{\mathrm{a}, \mathrm{b}}$ & 9.23 & 3 & 0.026 \\
\hline Tenure & & & & & 10.40 & 3 & 0.015 \\
\hline Socially rented & $7.1 \%^{\mathrm{a}}$ & $22.4 \%^{\mathrm{b}}$ & $8.2 \%{ }^{a, b}$ & $13.5 \%^{\mathrm{a}, \mathrm{b}}$ & & & \\
\hline Owner occupied & $90.5 \%^{a}$ & $71.8 \%^{a}$ & $86.4 \%^{a}$ & $81.1 \%^{a}$ & & & \\
\hline Equivalized income & & & & & 13.84 & 6 & 0.032 \\
\hline Up to $£ 13999$ & $42.1 \%^{\mathrm{a}}$ & $27.6 \%^{a, b}$ & $19.6 \%^{\mathrm{b}}$ & $37.5 \%{ }^{a, b}$ & & & \\
\hline$£ 14$ 000-33999 & $36.8 \%^{\mathrm{a}}$ & $36.8 \%^{a}$ & $38.0 \%^{\mathrm{a}}$ & $46.9 \%^{\mathrm{a}}$ & & & \\
\hline$£ 34000$ or more & $21.1 \%^{a, b}$ & $35.5 \%^{a, b}$ & $42.4 \%{ }^{\mathrm{b}}$ & $15.6 \%^{\mathrm{a}}$ & & & \\
\hline
\end{tabular}

Notes: Superscripts indicate significant differences between clusters; if two values do not share a letter, they are significantly different.

For test values: $\chi^{2}$ specifies the chi-square value obtained in the respective tests, d.f. the corresponding degrees of freedom, and $p$ the probability value.

Privately rented accommodation was omitted from the tenure analysis due to very low case numbers in all four clusters.

Building type differentiated between detached, semidetached, terraced and flat (purpose-built and converted). Five buildings were excluded from this analysis as they were characterized as other (e.g. a caravan). Bungalows formed part of the categories detached, semi-detached or terraced, depending on their specification. Cluster 2 (flat line) had significantly fewer detached dwellings than cluster 1 (steady up), and had significantly more flats than any other cluster. The majority of dwellings in all clusters had gas central heating (at least $78 \%$ ), so differences in other heating systems only represent a very small number of dwellings. A significant finding is a larger share of night storage heaters in cluster 2 (flat line) than in cluster 3 (two peak) and higher electricity consumption but not total energy consumption (not shown in detail). No other building variables differed between clusters (see Table A1 in Appendix A): wall type, total energy consumed (based on meter readings), amount of double-glazing, amount of draught-proofing of windows, amount of roof insulation, wall $U$-value, roof $U$-values and draught-proofing of external doors were not significantly different across clusters. Also variables related to the use of the thermostat and the total energy consumption based on meter readings for the winter monitoring period did not differ between clusters; the latter variable had a large number of missing data (valid $N=189$ ), which made is less likely to find differences between groups.

\section{Discussion and conclusions}

A CA performed on a temperature data set of 275 homes in England over three winter months resulted in four different clusters of temperature profiles. The

Table 5 Differences in socio-demographic continuous variables

\begin{tabular}{|c|c|c|c|c|c|c|c|}
\hline \multirow[t]{2}{*}{ Variable } & \multicolumn{4}{|c|}{ Cluster number } & \multicolumn{3}{|c|}{ Test } \\
\hline & 1 (Steady rise) & 2 (Flat line) & 3 (Two peak) & 4 (Steep rise) & $F$ & d.f. & $p$ \\
\hline Age of oldest person & $61.64^{\mathrm{a}, \mathrm{b}}$ & $54.52^{\mathrm{a}}$ & $54.77^{\mathrm{a}}$ & $65.37^{\mathrm{b}}$ & 6.91 & 3,271 & $<0.001$ \\
\hline Age of HRP & $61.07^{\mathrm{a}, \mathrm{b}}$ & $53.64^{\mathrm{b}, \mathrm{c}}$ & $53.77^{\mathrm{c}}$ & $63.55^{\mathrm{a}}$ & 6.26 & 3,271 & $<0.001$ \\
\hline Age of youngest person & $49.76^{a, c, d}$ & $36.66^{\mathrm{b}}$ & $40.55^{\mathrm{b}, \mathrm{c}, \mathrm{d}}$ & $53.89^{a}$ & 5.23 & 3,271 & 0.002 \\
\hline
\end{tabular}

Note: HRP $=$ household reference person. 
Table 6 Chi-squared analysis of building variables between clusters

\begin{tabular}{|c|c|c|c|c|c|c|c|}
\hline \multirow[t]{2}{*}{ Variable } & \multicolumn{4}{|c|}{ Cluster number } & \multicolumn{3}{|c|}{ Test } \\
\hline & 1 (Steady up) & 2 (Flat line) & 3 (Two peak) & 4 (Steep up) & $\chi^{2}$ & d.f. & $p$ \\
\hline Building type & & & & & 27.24 & 9 & 0.001 \\
\hline Detached & $50.0 \%^{a}$ & $22.4 \%^{\mathrm{b}}$ & $35.5 \%^{\mathrm{a}, \mathrm{b}}$ & $34.2 \%^{a, b}$ & & & \\
\hline Semi-detached & $26.2 \%^{\mathrm{a}}$ & $29.4 \%^{\mathrm{a}}$ & $30.9 \%^{a}$ & $28.9 \%^{\mathrm{a}}$ & & & \\
\hline Terraced & $19.0 \%^{\mathrm{a}}$ & $20.0 \%^{a}$ & $26.4 \%^{\mathrm{a}}$ & $26.3 \%^{\mathrm{a}}$ & & & \\
\hline Flats & $4.8 \%^{\mathrm{a}}$ & $27.4 \%^{b}$ & $6.4 \%^{\mathrm{a}}$ & $2.9 \%^{a}$ & & & \\
\hline Main heating & & & & & 20.80 & 9 & 0.014 \\
\hline Central heating: gas and liquefied petroleum gas & $83.3 \% \%^{a, b, c}$ & $77.6 \%{ }^{\mathrm{c}}$ & $91.8 \%{ }^{\mathrm{b}}$ & $78.9 \%^{\mathrm{a}, \mathrm{c}}$ & & & \\
\hline Central heating: other & $11.9 \%^{\mathrm{a}}$ & $4.7 \%^{a}$ & $4.5 \%{ }^{\mathrm{a}}$ & $5.3 \%^{\mathrm{a}}$ & & & \\
\hline Night electric storage heaters & $2.4 \%^{a, b, c}$ & $9.4 \%^{\mathrm{c}}$ & $0.0 \%{ }^{b}$ & $5.3 \%{ }^{a, c}$ & & & \\
\hline Other & $2.4 \%^{\mathrm{a}}$ & $8.2 \%^{a}$ & $3.6 \%^{a}$ & $10.5 \%^{\mathrm{a}}$ & & & \\
\hline
\end{tabular}

clusters differ significantly in their shape, as revealed by visual inspection, and supported by significant differences in minimum and maximum temperatures and standard deviations across the day. The largest cluster showed two peaks in internal temperature, one in the early morning and one in the evening, most closely in line what would be expected under standard (i.e. BREDEM) assumptions. However, the other three clusters that make up more than half the sample showed no such bimodal pattern, with one flat temperature cluster profile and two steadily increasing temperature profiles from early morning onwards. This finding challenges the assumption that one standard pattern fits all homes, and that the assumed BREDEM pattern of bimodal temperature pattern for weekdays represents how people generally operate their home. The analysis not only challenges the general assumption of a bimodal heating pattern for weekdays but also the assumption of a stark difference in heating patterns between weekdays and weekends. The cluster profiles are very similar for weekdays and weekends, casting doubt on the large difference of seven hours in heating duration assumed in BREDEM class models. It is important to keep in mind that internal temperatures do not directly indicate the status of the heating system but are a proxy for its usage. This might partly explain the finding that clusters did not vary significantly in their average temperatures, i.e. that no particular shape is strongly linked to a higher or lower average temperature. Data were centralized in order to detect shapes in the data; non-centralized data were also compared between clusters; hence, a linkage between profile shape and temperature would have been found if it existed. Had the respective maximum temperatures in each of the clusters been the same, say arising from a common demand temperature across all households, then homes with flat profiles would have been expected to have a higher internal temperature averaged over the whole of the heating season than homes where the hourly heating season average temperatures vary strongly over the course of a day (such as the two peak). In this case, the flat profile would have had a higher average internal temperature because the maximum temperature would have been very close to the average, whereas the bimodal pattern would have only reached temperatures close to the maximum twice a day with much lower temperatures throughout the remaining hours. However, it was found that the flat profile had a peak temperature that was about $1{ }^{\circ} \mathrm{C}$ lower than that of the two-peak pattern, resulting in the same average daily temperature in both clusters. Hence, regarding the prediction of energy demand for individual homes, and the prediction of future energy demand, the temperature profiles as shown in this analysis are of little importance.

However, the presence of different temperature profile clusters may have important implications for power demand. Peak power demand for heating is becoming a key energy infrastructure constraint in the context of proposals for increasing electrification of domestic heat supply through use of heat pumps and electric resistive heating powered through a decarbonized national electricity system. While this analysis focuses on winter averages, further research is needed to determine whether similar clusters can be observed on data for individual days (HM Government, 2011; Strbac et al, 2012).

Capturing the shape of temperature patterns over the span of a day may also aid in assessing what sectors 
of the population would be most suitable for different heating technologies. For example, dwellings with little variation of temperatures over the course of the day might be more suitable for heat pumps that are most efficient when delivering constant background heat (Caird, Roy, \& Potter, 2012). Irrespective of whether such profiles arose from occupant preferences or through building characteristics, the occupants would be used to such a temperature profile and therefore may adjust better to the flat profiles provided by heat pumps. Similarly, identification of temperature profile shapes aids in assessing forms of building fabric retrofit that may be more suitable to different population segments. Population segments with flat profiles may adjust more readily to homes with high levels of insulation and mechanical ventilation, housing characteristics that are associated with flattening of profiles. In addition, the distinctively different shapes might reflect different comfort requirements, the thermal performance of different building forms and fabrics, or the different characteristics of heating systems. A closer look at the difference in building characteristics and socio-demographics is of interest in this regard. Cluster 4 (steep rise) has an older household member composition; qualitative studies of elderly people find they often report ventilating bedrooms at night (Day \& Hitchings, 2011; Wright, 2004) which could contribute to the stark decline observed in the cluster shape, assuming that either living rooms are also ventilated or affected by the cold air coming into the bedroom. Cluster 2 (flat line) has more flats and social housing tenants and a larger share of homes with children. Cluster 3 (two peak) has rather higher income consisting of more houses and a smaller proportion of low-income households. The findings of more flats in the flat line profile (cluster 2) makes sense given that flats have generally less heat loss because of a smaller external surface area (Shorrock \& Utley, 2008). The presence of more small children in this cluster might contribute to explaining the relatively higher night temperature if parents are worried about their children getting cold at night. A higher income and neither a particularly young nor old household as in the cluster profile 3 (two peak) could indicate a household with working adults who leave the house during the day. The relatively older cluster 4 (steep rise) might indicate the presence of retired tenants who turn the heating off at night, and then turn it on early and steadily as they stay at home most of the day. However, given that capacity to explain the differences between clusters with the available variables is limited, no discrete characterization of each cluster is possible, and a better understanding of what drives the apparent differences in temperature patterns requires further research. In particular, given that the sample was not fully representative of the English population, it cannot claim to have detected all typical patterns of heating and identified all linkages between socio-demographic and building variables. However, the work constitutes an important first step in showing patterns of temporal variation over the course of the day. The analysis showed that one general pattern does not fit how homes are used; homes exhibit distinctly different patterns of temperature over the course of the day. What exactly these differences reflect needs to be addressed in further research.

\section{Acknowledgements}

The authors would like to thank Kevin Lomas, Steven Firth, Andrew Wright and Mike Gentry for their contribution in creating and managing the dataset; and to thank the sponsors for their support.

\section{Funding}

This work was done under the 'People Energy and Buildings: Distribution, Diversity and Dynamics' project [number EP/H051112/1] in partnership with the EDF European Energy Efficiency Research Centre (ECLEER) and funded by the Engineering and Physical Sciences Research Council (EPSRC) and EDF Energy. The data analysed in this paper are drawn from the CaRB Home Energy Survey conducted as part of the Carbon Reduction in Buildings project [number GR/ S94377/01].

\section{References}

Allcott, H., \& Mullainathan, S. (2010). Behavior and energy policy. Science, 327, 1204-1205. doi:10.1126/science. 1180775

Anderson, B. R., Chapman, P. F., Cutland, N. G., Dickson, C. M., Doran, S. M., Henderson, G., ..., Shorrock, L. D. (2002). BREDEM-8 Model description: 2001 update (BR439). Watford: Building Research Establishment \& Department for Environment, Food \& Rural Affairs.

Caird, S., Roy, R., \& Potter, S. (2012). Domestic heat pumps in the UK: User behaviour, satisfaction and performance. Energy Efficiency, 5, 283-301. doi:10.1007/s12053-012-9146-x

CarbonTrust. (2012). Degree days for energy management. Retrieved from Carbon Trust website: http://www. carbontrust.com/media/137002/ctg075-degree-days-forenergy-management.pdf

Cayla, J.-M., Allibe, B., \& Laurent, M.-H. (2010). From practices to behaviors: Estimating the impact of household behavior on space heating energy consumption. American Council for an Energy-Efficiency Economy (ACEEE) Summer Study on Energy Efficiency in Buildings, 7.26-7.38. Retrieved from http://www.aceee.org/files/proceedings/ 2010/data/papers/2141.pdf

Clatworthy, J., Buick, D., Hankins, M., Weinman, J., \& Horne, R. (2005). The use and reporting of cluster analysis in health psychology: A review. British Journal of Health Psychology, 10(3), 329-358.

Committee on Climate Change. (2010). The fourth carbon budget: Reducing emissions through the 2020s. London: Committee on Climate Change.

Day, R., \& Hitchings, R. (2011). 'Only old ladies would do that': Age stigma and older people's ways of dealing with winter cold. Health Place, 17(4), 885-894. doi:10.1016/j. healthplace.2011.04.011 
Department of Communities and Local Government. (2010). English house condition survey 2007: Technical Report. Retrieved from http://webarchive.nationalarchives.gov. uk/20120919132719/http://www.communities.gov.uk/ documents/housing/pdf/1617931.pdf

Department of Communities and Local Government. (2011) English House Condition Survey, 2007 [Data set]. $2^{\text {nd }}$ Edition. Retrieved April 9, 2013, from UK Data Archive [distributor]. SN 6449. doi:10.5255/UKDA-SN-6449-1

Department of Energy and Climate Change. (2008). Climate change act 2008. London: Department of Energy and Climate Change.

Dietz, T., Gardner, G. T., Gilligan, J., Stern, P. C., \& Vanderbergh, M. P. (2009). Household actions can provide a behavioral wedge to rapidly reduce U.S. carbon emissions. Proceedings of the National Academy of Sciences of the United States of America, 106, 18452-18456. doi:10. 1073/pnas.0908738106

Druckman, A., \& Jackson, T. (2008). Household energy consumption in the UK: A highly geographically and socioeconomically disaggregated model. Energy Policy, 36(8), 3177-3182. doi:10.1016/j.enpol.2008.03.021

Firth, S. K., Lomas, K. J., \& Wright, A. J. (2010). Targeting household energy-efficiency measures using sensitivity analysis. Building Research \& Information, 38, 25-41. doi:10. 1080/09613210903236706

French, L. J., Camilleri, M. J., Isaccs, N. P., \& Pollard, A. R (2007). Temperatures and heating energy in New Zealand houses from a nationally representative study-HEEP. Energy and Buildings, 39, 770-782.

Gill, Z. M., Tierney, M. J., Pegg, I. M., \& Neil, A. (2010). Lowenergy dwellings: The contribution of behaviours to actual performance. Building Research \& Information, 38(5), 491-508. doi:10.1080/09613218.2010.505371

HM Government. (2011). The carbon plan: Delivering our low carbon future. Retrieved from https://www.gov.uk/ government/uploads/system/uploads/attachment_data/file/ 47613/3702-the-carbon-plan-delivering-our-low-carbonfuture.pdf

Huebner, G. M., McMichael, M., Shipworth, D., Shipworth, M., Durand-Daubin, M., \& Summerfield, A. (2013). Heating patterns in English homes: Comparing results from a national survey against common model assumptions. Building and Environment, 70, 298-305. http://dx.doi.org/10. 1016/j.buildenv.2013.08.028

Hughes, M., Palmer, J., Cheng, V., \& Shipworth, D. (2013). Sensitivity and uncertainty analysis of the UK's housing energy model. Building Research and Information, 41(2), 156167. doi:10.1080/09613218.2013.769146

Hunt, D. R. G., \& Gidman, M. I. (1982). A national field survey of house temperatures. Building and Environment, 17, 107124. doi:10.1016/0360-1323(82)90048-8

Isaksson, C., \& Karlsson, F. (2006). Indoor climate in low-energy houses-An interdisciplinary investigation. Building and Environment, 41, 1678-1690.

Kane, T., Firth, S., Allinson, D., Irvine, K., \& Lomas, K. (2010). Does the age of the residents influence occupant heating practice in UK domestic buildings? Paper presented at the East Midlands Universities Association 2010 Conference Perspectives in Society: Health, Culture, and the Environment, University of Leicester. Retrieved from http://mmmm.lboro. ac.uk/doc/EMUA\%20conference\%20paper.pdf

Kavgic, M., Mavrogianni, A., Mumovic, D., Summerfield, A., Stevanovic, Z., \& Djorovic-Petrovic, M. (2010). A review of bottom-up building stock models for energy consumption in the residential sector. Building and Environment, 45, 1683-1697. doi:10.1016/j.buildenv.2010.01.021

Kelly, S. (2011). Do homes that are more energy efficient consume less energy?: A structural equation model of the English residential sector. Energy, 36, 5610-5620. doi:10.1016/j. energy.2011.07.009

Kelly, S., Shipworth, M., Shipworth, D., Gentry, M., Wright, A., M. Pollitt, ..., Lomas, K. (2013). A panel model for predicting the diversity of internal temperatures from English dwellings. Applied Energy, 102, 601-621. doi:10.1016/j. apenergy.2012.08.015

Lutzenhiser, L. (1993). Social and behavioural aspects of energy use. Annual Review of Energy and the Environment, 18, 247-289. doi:10.1146/annurev.eg.18.110193.001335

Nowak, T. (2009). Energy Use in Homes 2007: A series of reports on domestic energy use in England - Space and WaterHeating. Watford: BRE Housing. Retrieved from http://www. bre.co.uk/filelibrary/pdf/rpts/Space_and_Water_Heating_ 2007.pdf

ONS. (2012). Harmonised concepts and questions for social data sources: Primary standards - demographic information, household composition and relationships. London: Office of National Statistics. Retrieved from http://www.ons.gov. uk/ons/guide-method/harmonisation/primary-set-of-harmon ised-concepts-and-questions/demographic-information-hou sehold-composition-and-relationships.pdf

Oreszczyn, T., Hong, S., Ridley, I., \& Wilkinson, P. (2006). Determinants of winter indoor temperatures in low income households in England. Energy and Buildings, 38, 245252. doi:10.1016/j.enbuild.2005.06.006

Oreszczyn, T., \& Lowe, R. (2004). Science and Technology Minutes of Evidence: Memorandum by Professor Tadj Oreszczyn and Professor Robert Lowe, House of Lords Select Committee on Science and Technology. Retrieved from http://www.publications.parliament.uk/pa/ld200506/ ldselect/ldsctech/21/4111702.htm

Shipworth, M., Firth, S. K., Gentry, M. I., Wright, A. J., Shipworth, D. T., \& Lomas, K. J. (2010). Central heating thermostat settings and timing: Building demographics. Building Research \& Information, 38, 50-69. doi:10. 1080/09613210903263007

Shorrock, L. D., \& Utley, J. I. (2008). Domestic energy fact file 2008. Watford: Building Research Establishment.

Strbac, G., Aunedi, M., Pudjianto, D., Djapic, P., Gammons, S., \& Druce, R. (2012). Understanding the balancing challenge. London: Imperial College London and NERA Economic Consulting. Retrieved from https://www. gov.uk/government/uploads/system/uploads/attachment data/file/48553/5767-understanding-the-balancing-chall enge.pdf

Utley, J. I., \& Shorrock, L. D. (2006). Domestic energy fact fileOwner occupied, local authority, private rented and registered social landlord homes. Watford: Building Research Establishment.

Ward, J. H. (1963). Hierarchical grouping to optimize an objective function. Journal of the American Statistical Association, 58, 236-244.

Wright, F. (2004). Old and cold: Older people and policies failing to address fuel poverty. Social Policy o Administration, 38(5), 488-503. doi:10.1111/j.1467-9515.2004.00403.x

\section{Endnotes}

${ }^{1}$ English homes refers only to homes in England, not the UK in total. Hence, results and interpretation are limited to homes in England.

${ }^{2}$ The household reference person refers either to the sole owner or the tenant of a property, or, if there is more than one occupant, the person with the highest income, and in the case of equal incomes, the oldest of those. This is according to the Office of National Statistics definition (ONS 2012). 


\section{Appendix A}

Table A1 Variables that did not differ between clusters

Variable

\begin{tabular}{|c|c|}
\hline $\begin{array}{l}\text { Number of persons in a household aged } \\
\text { under } 18\end{array}$ & Continuous \\
\hline $\begin{array}{l}\text { Number of persons in a household aged } \\
\text { under } 14\end{array}$ & Continuous \\
\hline Household size & $1,2,3,4,5$ people or more \\
\hline Household type & Single, couple, dependent children, other \\
\hline Number of bedrooms & Continuous \\
\hline Wall type & Cavity wall, solid wall, other \\
\hline Cavity wall insulation & Yes, no \\
\hline Roof insulation & Yes, no \\
\hline Roof $U$-value & $<0.40,0.40,>0.40$ \\
\hline Windows double-glazed & All, some, none \\
\hline Windows draught-proofed & All, some, none \\
\hline External doors draught-proofed & All, some, none \\
\hline Times for $\mathrm{CH}$ regular on weekdays & Yes, no \\
\hline Timer or manual operation of $\mathrm{CH}$ & Timer, manual \\
\hline Ease of access to timer of the $\mathrm{CH}$ system & Very easy, fairly easy, not easy \\
\hline $\begin{array}{l}\mathrm{CH} \text { thermostat setting changes for a typical } \\
\text { day }\end{array}$ & $0,1,2,>2$ per day \\
\hline $\mathrm{CH}$ time control & $\begin{array}{l}\text { None, timer, programmable room thermostat, } \\
\text { unknown or other type of thermostat or timer }\end{array}$ \\
\hline $\mathrm{CH}$ thermostat - do you ever turn it up? & Yes, no \\
\hline $\mathrm{CH}$ thermostat - main way to turn it up? & Until clicks, high to warm fast, specific number, other \\
\hline $\mathrm{CH}$ temperature control & $\begin{array}{l}\text { None, room stat (room thermostat), TRV (thermostatic radiator valves) only, prog stat } \\
\text { (programmable thermostat) }\end{array}$ \\
\hline $\begin{array}{l}\text { Are } \mathrm{CH} \text { hours on weekdays and weekends } \\
\text { the same? }\end{array}$ & Yes, no \\
\hline Gas $2007 / 08 \mathrm{kWh}$ annualized, i.e. 365 days & Continuous \\
\hline Gas $2007 / 08$ winter average kWh/day & Continuous \\
\hline
\end{tabular}

Notes: There was no difference in the distribution of government office regions (GOR) across the clusters. Since external temperatures were measured at the spatial resolution of GORs, the average winter temperature was the same for all homes within one GOR. Since the distribution of GORs did not differ between clusters, also the distribution of the external winter temperature did not differ between clusters. However, this needs to be interpreted with caution and not in the way that external temperatures do not exert an impact on internal temperatures. However, for an exploration of that question, a more detailed analysis would be needed on a day-by-day basis ideally with temperature data of greater spatial accuracy.

$\mathrm{CH}=$ central heating 